\title{
O detalhe e o macro-contexto: o uso da teoria centrada no Estado para explicar práticas e políticas educacionais*
}

\author{
The detail and the bigger picture: the \\ use of state-centred theory in \\ explaining education policy and practice
}

\author{
Sally POWER ${ }^{* *}$
}

\begin{abstract}
Resumo: Neste artigo, por meio da teoria centrada no estado, procura-se compreender mudanças ocorridas recentemente em escolas inglesas. Para tanto, consideram-se as preocupações expressas por Jenny Ozga, a qual afirma que muitas pesquisas sobre política e prática educacional ignoram o macro-contexto. Com base em dados de estudos de caso, argumenta-se que teorizações sobre as políticas educacionais que se fundamentam em concepções centradas no Estado oferecem pouca ajuda na compreensão do que acontece nas escolas. Sugere-se que, ao invés de denegrir o 'empiricismo' das pesquisas, dever-se-ia reconsiderar a utilidade dos referenciais macro-analíticos. Defende-se a idéia de que tais referenciais podem ser baseados em suposições que a princípio não são passíveis de serem demonstradas, assim como em oposições que não são facilmente defensáveis.
\end{abstract}

Palavras-chave: política educacional. macro. micro contexto.

Abstract: This paper attempts to understand recent changes on schools through the use of state-centred theory. It does so in the light of concerns expressed by Jenny Ozga that much research on education policy and practice ignores de "bigger-picture". Through using case study material, this paper argues that state-centred theorizations of education policy may provide little help in explicating what is going on in schools. The paper suggests that, rather than denigrating the "empiricism" of research, we should reconsider

\footnotetext{
* Tradução do artigo "The Detail and the Bigger Picture: the use of state-centred theory in explaining education policy and practice", publicado no International Studies in Sociology of Education, v. 5, n.1, 1995, p. 77-92. A Revista Olhar de Professor agradece a autora pela autorização da tradução e publicação. Tradução de Thaisa de Andrade (UEPG). As notas explicativas (N.E.) foram elaboradas pelo Prof. Dr. Jefferson Mainardes (UEPG).

** Foi Professora do Institute of Education/University of London. Atualmente é Professora da Cardiff University - País de Gales (Nota Explicativa).
}

Olhar de professor, Ponta Grossa, 9(1): 11-30, 2006. 
the usefulness of such macro-analytical frameworks. It argues that these may be based on a priori assumptions which are undemonstrable and oppositions which are untenable.

Keywords: education policy. macro. micro context.

\section{INTRODUÇÃO}

Neste artigo procuramos explicar aspectos da recente mudança ocorrida em escolas inglesas, tendo como referência uma estrutura macro-analítica. Em particular, discutimos a utilidade da teoria marxista centrada no Estado para a explicação de processos locais. O texto surge não somente de uma preocupação pessoal de compreender a pesquisa que foi realizada recentemente ${ }^{1}$, mas também de responder às críticas da pesquisa feita há cinco anos por Jenny Ozga (1990). Ozga argumenta que a política "Grant-maintained schools project" - GM Schools (HALPIN; FITZ; 1990; FITZ et al, 1993) $)^{2}$, assim como muitas outras pesquisas sobre política educacional, havia se concentrado nos detalhes, não considerando o macrocontexto. Um referencial mais amplo, tal como a abordagem centrada no Estado, poderia, segundo a autora, fornecer um sentido muito mais coerente sobre o que estava acontecendo nas escolas.

No entanto, a partir de dados obtidos da pesquisa sobre GM Schools, é possível afirmar que formulações teóricas do tipo das sugeridas por Ozga (DALE; OZGA, 1991; OZGA, 1993) oferecem poucos elementos para explicar processos locais. Além disso, constata-se que o problema de relacionar macro e micro está tanto no referencial que fundamenta uma análise do macro-contexto quanto na "descrição" das pesquisas. Longe de fornecer a chave para compreender o macro-contexto, a teoria centrada no

\footnotetext{
${ }^{1}$ A pesquisa citada no artigo e da qual o material de estudo de caso foi retirado foi realizada por John Fitz e David Halpin. A pesquisa foi financiada pelo Economic and Social Research Council.

${ }^{2}$ Grant-maintained schools foi uma política introduzida no Reino Unido, pelo governo conservador, com a Reforma Educacional de 1988. As escolas poderiam optar por desligarse da autoridade educacional local e tornarem-se GM Schools, diretamente vinculadas ao governo central. Na prática, as escolas poderiam tornar-se comunitárias, fundações ou escolas voluntárias. Seus defensores acreditavam que esse tipo de escola aumentaria as possibilidades de escolha dos pais e melhoraria o padrão de qualidade das escolas. O número de GM Schools cresceu gradualmente e, em 1996, havia 1.090 escolas, sendo que $60 \%$ delas eram escolas secundárias (alunos de 11 a 16 anos). Tal política foi encerrada em 1998, por um ato do Governo Trabalhista (N.E.).
}

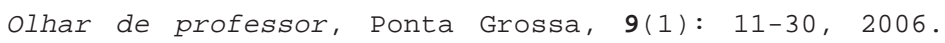


Estado parece estar baseada em suposições que não são passíveis de serem demonstradas e em oposições que não são facilmente defendidas.

\section{ANTECEDENTES}

Em 1990, David Halpin e John Fitz publicaram os resultados da pesquisa realizada com financiamento do Economic and Social Research Council (Conselho de Pesquisa Econômica e Social), cujo objetivo foi investigar a origem e impacto da política GM Schools (HALPIN; FITZ, 1990). O artigo desencadeou uma resposta de Jenny Ozga, em que ela divulgava algumas preocupações sobre as tendências atuais da análise de política e pesquisa educacional (OZGA, 1990), argumentando que a referida pesquisa sobre o projeto $G M$ Schools e outros semelhantes não levavam em conta a "necessidade de relacionar aspectos estruturais, macro-análise dos sistemas educacionais... e investigação em nível micro" (p. 359). Com particular referência ao projeto GM Schools, Ozga então comenta:

O conteúdo e estilo da discussão, e em particular o peso dado ao acúmulo de informação sobre GM Schools me faz lembrar o caso de estudos sobre a formulação de políticas educacionais no período anterior a ERA (Education
Reform Act). ${ }^{3}$ A principal característica desses estudos era a riqueza do cenário apresentado e o detalhamento da descrição. Isto estava relacionado à limitada - ou totalmente ausente consideração de questões mais amplas, tais como que papel o relato detalhado de uma questão específica exercia na criação de um contexto mais amplo e qual perspectiva teórica subsidiava os seus estudos... Porque nossas percepções daquele período são tão imbuídas de interpretações pluralistas que parecem meras descrições, nós perdemos de vista a coerência da política educacional, sua natureza essencialmente diferenciada, suas funções consistentes e contradições associadas. Os perigos de uma ênfase demasiada na diversidade e devolução ${ }^{4}$ são especialmente fortes agora, depois do ERA. (OZGA, 1990, p. 360)

Embora reconhecendo a validade das críticas ao funcionalismo, a autora entende que “... há, talvez, um perigo de que nós estejamos indo muito longe em uma única direção, encorajados pelo clima para nos mantermos afastados das agendas que focalizam a teorização do papel do Estado na educação, preocupados em acumular descrições, sem pensar o suficiente na natureza do objeto a ser descrito" (p. 360). Para ela, isso levará a uma situação na qual "... nós continuaremos a desmontar e descrever todas as partes da engrenagem sem sermos capazes de explicar como ela funcio-

${ }^{3}$ Ato de Reforma Educacional 1988 (N.E).

${ }^{4}$ Transferência de responsabilidade ou descentralização de uma esfera para outra (N.E).

Olhar de professor, Ponta Grossa, 9(1): 11-30, 2006. $\overline{13}$ 
na ou para que ela serve". A autora conclui sua resposta argumentando que sem uma estrutura explanatória mais ampla, tal como a que oferece a teoria centrada no Estado, "nós estaremos ocupados, mas cegos" (p. 361).

Agora que a política GM Schools chegou ao seu final, este artigo oferece uma oportunidade de retornarmos à crítica de Ozga e reexaminar a validade da sua afirmação de que a teoria centrada no Estado é capaz de prover explicações teoricamente mais adequadas e coerentes sobre a textura e a direção das mudanças educacionais.

O questionamento crítico sobre as macro-teorizações não é algo novo. Tem havido muitos debates sobre o que é uma análise conjuntural e sobre o grau de determinância do que acontece 'abaixo'. Em relação a um modelo de política educacional centrada no Estado, Ball argumenta que este não pode explicar adequadamente a mudança (BALL, 1990), enquanto que Raab (1994) comenta que o Estado incorpora apenas uma fraca noção de agência ${ }^{5}$. Bowe et al (1992) chamam a atenção para as conseqüências negativas de abordagens top down ${ }^{6}$, afirmando que teorias centradas no Estado servem a um "propósito ideológico poderoso" de tirar ainda mais o poder dos sujeitos. De modo especial, o trabalho de Ozga (assim como o de Dale) tem sido criticado pela sua definição arbitrária de Estado (RAAB, 1994) e sua interpretação errônea de outras abordagens marxistas (HATCHER; TROYNA, 1994).

Todavia, tais críticas são freqüen-temente relacionadas apenas a questões teóricas. Como Bernstein (1977) argumenta, modelos tendem a se justapor continuamente em termos de suas suposições subjacentes de estrutura ou sujeito, ao invés de serem examinados em termos de suas propriedades conceituais e empíricas. De fato, Bernstein sugere que "a forma que tal questionamento toma pode obscurecer nosso entendimento" (1977, p.157). A adequação teórica não se baseia apenas em princípios sólidos e consistência interna: ela também depende de testabilidade empírica (SAUNDERS, 1986; WRIGHT et aL,1992). Portanto, ao invés de nos engajarmos, neste artigo, em debates sobre as premissas da teoria centrada no Estado, consideramos as

\footnotetext{
${ }^{5}$ O termo agency, neste contexto, significa as ações e motivações humanas. Os "agentes" possuem um potencial de mudar as estruturas. Estrutura, por sua vez, é o contexto social, econômico e político no qual as ações ocorrem. O debate entre "estrutura" (structure) e "sujeito" (agency) é um dos aspectos que têm sido bastante debatidos nas Ciências Sociais (N.E).

6 Top-down (“de cima para baixo") refere-se à forma como as políticas podem ser implementadas ou analisadas (N.E).
} 
dificuldades de usá-la ${ }^{7}$. Qual a utilidade de se relacionar macro e microestruturas; detalhe e contexto mais amplo?

\section{OMACRO-CONTEXTO}

Em uma abordagem estadocêntrica, as teorizações sobre política educacional representam uma tentativa de aderir a uma compreensão marxista das relações sociais e, ao mesmo tempo, reconhecer a complexidade dos processos sociais. Tendo como base o trabalho de Poulantzas (1973) e Offe $(1975,1984,1985)$, entre outros, os teóricos que adotam uma perspectiva estadocêntrica procuram desvendar a relação emaranhada e contraditória entre o Estado, classe e capital que está relacionada com as políticas educacionais e as práticas escolares. Na Grã-Bretanha (e na Nova Zelândia), os principais recontextualizadores têm sido Jenny Ozga e Roger Dale, ambos escrevendo individualmente (por exemplo: DALE, 1989; OZGA, 1993) e em parceria (DALE; OZGA, 1991). Apenas um breve esboço do referencial criado por eles pode ser apresentado aqui, baseado principalmente na "versão preliminar" apresentada à Open University sobre a elaboração de po- líticas em educação (DALE; OZGA, 1991; OZGA, 1993).

Teóricos da abordagem estadocêntrica, como Dale e Ozga, comentam que o ponto de partida para qualquer análise adequada de política e prática educacional deve envolver o reconhecimento do Estado e da sua relação com o capital. No entanto, na sua rejeição às simples teorias de correspondência (por exemplo, BOWLES; GINTIS, 1976), eles argumentam que a função do Estado não pode ser reduzida a aspectos ligados à economia. Por outro lado, isso não significa que o Estado age de forma autônoma. Ele tem um conjunto permanente de problemas que surgem da necessidade de capital. Dentre eles, três, em particular, podem ser identificados: primeiramente, há a necessidade de apoiar o processo de acúmulo de capital; em segundo lugar, o Estado deve garantir um contexto para a sua expansão contínua; finalmente, $o$ Estado precisa legitimar o modo capitalista de produção, incluindo sua própria parte nesse processo.

No entanto, e novamente de forma diferente de teses de simples correspondência, a resolução desses problemas centrais não é simples, nem garantida. Primeiro, os problemas são inerentemente contraditórios, na me-

${ }^{7} \mathrm{O}$ ideal, é claro, é que a relação entre os dados e o referencial teórico seja definida antes da coleta. No entanto, embora este seja o caso em que a coleta e a interpretação de 'evidências' empíricas são indubitavelmente estabelecidas por valores, tais valores não precisam evitar a interrogação teórica dos dados de diferentes perspectivas. Nessa relação, Saunders (1986) faz uma importante distinção entre dependência teórica e determinância teórica.

Olhar de professor, Ponta Grossa, 9(1): 11-30, 2006. $\overline{15}$ 
dida em que não podem ser resolvidos simultaneamente. Em segundo lugar, o escopo das políticas é mediado pelo que é possível de ser atingido pelos sistemas educacionais. $\mathrm{E}$ enquanto amplos mandatos são identificados em conexão com, por exemplo, a provisão de uma força de trabalho adequadamente habilitada, qualificada e estratificada, o cumprimento desses mandatos não é automático.

Apesar dessa indeterminância, a fonte e escopo das políticas educacionais estabelecem os parâmetros que dão forma ao impacto e efeitos no micro nível. De novo, embora Dale e Ozga evitem simples relações de causa e efeito, ao nível de processos locais, por exemplo, "Os parâmetros estabelecem o padrão, mas não o determinam, porque há discursos sobre currículo, pedagogia, avaliação e organização escolar que não são redutíveis ao cumprimento das necessidades externamente geradas" (OZGA, 1993).

Resumindo, a teoria de Ozga e Dale (centrada no Estado) baseia-se numa afirmação a priori da centralidade do Estado, na sua relação com um modo capitalista de produção e suas contradições inerentes, junto com o reconhecimento de uma relativa indeterminância como resultado de especificidades históricas e contextuais. Essas especificidades são aparentes nos detalhes dos estudos de caso apresentados a seguir.

\section{ODETALHE}

Os estudos de caso apresentados compreendem quatro escolas envolvidas na pesquisa sobre GM Schools, as quais são citadas neste texto como Greenbank, Bellevue, Arneside e Northwood. Pelo fato de que apenas idéias gerais podem ser apresentadas aqui, elas inevitavelmente parecerão caricaturas e não as ricas descrições citadas anteriormente. No entanto, tais escolas oferecem um indicativo do alcance das respostas locais às reformas recentes em educação.

A Escola Greenbank, a primeira dos quatro estudos de caso, é freqüentada por alunos de ambos os sexos. Nela não existe seleção para ingresso e é uma escola que se tornou uma GMSchool. Está situada em uma das áreas urbanas mais pobres na Inglaterra e atende a uma grande comunidade asiática, sendo que as matrículas são de 80 a $90 \%$ de estudantes muçulmanos. Poder-se-ia imaginar que essa escola fosse favorecida com recursos pela autoridade educacional local, uma vez que esta possuía uma política explícita de expansão de oportunidades educacionais. Mas a sua campanha para tornar-se GM School baseou-se na negligência da autoridade local de educação. A necessidade da comunidade era entendida, pois, como forma de resposta à indiferença burocrática.

Ao rejeitar a autoridade local de educação, a Escola Greenbank fez várias tentativas de dar forma à sua 
identidade educacional. Construída na década de 70 , seus vidros simples e lisos e sua estrutura de concreto podem ser vistos como símbolo do otimismo modernista. Desde que se desligou da autoridade local de educação, distanciou-se do conceito de "escola comum" e optou pelo tradicionalismo do currículo inglês acadêmico e o reconhecimento da identidade étnica e herança da comunidade local.

A promoção de valores tradicionais está simbolizada na beca pendurada na sala do diretor. Também fica evidente na estruturação da escola, que desenvolveu um sistema de organização para alunos "mais inteligentes e adaptáveis", denominado $A$ stream. Porém, em vários aspectos, $\mathrm{o}$ reconhecimento da herança cultural e de valores da comunidade é aparente. O festival islâmico do Ramadan, por exemplo, é reconhecido e celebrado oficialmente na escola. Informações sobre a escola são publicadas nas línguas da comunidade e o background étnico dos seus alunos é enfatizado nas fotografias dos prospectos da escola. Em uma fotografia, por exemplo, pode-se ver um menino lendo um livro sobre o Islã. Greenbank introduziu o bengali e o urdu como línguas modernas nos exames do $\mathrm{GCSE}^{8}$ e ainda tem estudos islâmicos como uma das disciplinas optativas. Além disso, o estudo do urdu em nível de A level (nível avançado) será introduzido em breve no currículo do Sixth Form. ${ }^{9}$

A tensão entre essas duas dimensões do currículo e a sua resolução parcial é evidente no status diferenciado das escolhas oferecidas em termos de línguas. Alunos mais capazes (A-stream), por exemplo, têm permissão para estudar apenas francês: "a primeira língua moderna em algumas de nossas melhores escolas". Urdu e bengali são disponibilizados apenas para os alunos menos capazes academicamente. Da mesma forma, os estudos islâmicos, que não fazem parte das opções dos exames nacionais, não são disponibilizados para alunos mais capazes (A-stream).

Bellevue é uma escola para meninos de 11 a 18 anos na qual não há seleção para ingresso. Também é uma escola incluída no projeto $G M$ Schools. Diferentemente da Escola Greenbank, Bellevue está localizada em uma cidade pequena e próspera. A escola optou por desligar-se da autoridade local de educação, com o objetivo de evitar seu fechamento e trans-

\footnotetext{
${ }^{8}$ GCSE - General Certificate of Secondary Education é o exame nacional para alunos de 16 anos (N.T)

${ }^{9}$ Sixth form é termo utilizado no sistema educacional britânico para designar os estudos realizados pelos alunos após a escolarização obrigatória (5 a 16 anos). Esses estudos visam preparar os alunos para o exame nacional denominado A Level (Nível Avançado). Os alunos precisam desses exames para ingressar na Universidade (N.E).
}

Olhar de professor, Ponta Grossa, 9(1): 11-30, 2006. 
formação em um centro de Sixth Form. A maioria de seus alunos é de classe média.

Enquanto a Escola Greenbank tentou incorporar a tradição acadêmica e a diversidade cultural, Bellevue não teve tais dilemas. A escola alinhou-se de forma não ambígua a um modelo de educação tradicional. A defesa dessa imagem foi, em parte, uma resposta às vicissitudes do mercado.

A redescoberta da educação tradicional foi relativamente fácil, considerando-se que Bellevue era uma Grammar School ${ }^{10}$. Seu prédio imponente de pedras e saguão revestido de carvalho representa um legado educacional um tanto quanto diferente, em virtude da criação de regras, rotinas e cerimônias "arcaicas". O código de vestimenta dos alunos é rigidamente reforçado, assim como determinadas formas de referência. Dois pequenos detalhes dão uma idéia da extensão na qual a escola está redescobrindo tradição: a escola investiu 10.000 libras esterlinas em um órgão de tubos para o saguão; os alunos não devem mais usar o termo "cantina", e sim "refeitório".

A Escola Arneside, vinculada à autoridade local de educação, é uma escola para crianças de ambos os sexos, de 11 a 18 anos. Nela também não há exame de seleção. Está localizada em uma pequena cidade social e eco- nomicamente mista. Uma proporção considerável de seus alunos vem de background de profissionais de classe média. De fato, seus alunos têm um background sócio-econômico mais elevado que os da Grammar School vizinha.

Em contraste com as escolas Greenbank e Bellevue, a resposta da Escola Arneside à recente política tem sido a de enfatizar sua lealdade aos princípios e práticas de controle democrático local. Na verdade, é a única escola na vizinhança que permaneceu vinculada à autoridade local. Duas escolas vizinhas (Grammar Schools), ambas destinadas a alunos do mesmo sexo, saíram cedo do projeto $G M$ Schools. Uma outra escola secundária, ex-escola secundária moderna, optou por deixar de ser GM Schools, evitando assim ser "deixada para trás".

Ao reeenfatizar sua lealdade a uma visão inclusiva e não-seletiva, Arneside atrai pais profissionais, em especial os da nova classe média, para os quais a escola seletiva e valores evidentemente tradicionais divulgados pelas escolas da vizinhança são um anátema. Aidentidade de Arneside é, portanto, construída com base na educação não-seletiva, para ambos os sexos, e centrada na criança. Os alunos têm disciplinas eletivas, um código de vestimenta nada rígido e con-

${ }^{10}$ Grammar Schools são escolas secundárias (11 a 16 anos e 16 a 18) que oferecem uma formação acadêmica para alunos que desejam ingressar na universidade. São destinadas para alunos considerados "mais capazes" (N.E). 
selhos escolares. Diferentemente de Bellevue, há poucas regras e rituais. A hierarquia entre professores e alunos é menos visível. O calendário escolar da Escola Arneside é suspenso durante as semanas em que há projetos a serem desenvolvidos. Se Bellevue evoca uma imagem de meninos correndo por campos e estudando latim, a imagem de Arneside mostra alunos estudando disciplinas como psicologia e sociologia e participando na forte tradição escolar de arte e teatro.

Northwood é outra GM School. É uma escola para meninas de 11 a18 anos. A escola optou por desligar-se da autoridade local de educação para evitar a junção com a escola de meninos que estava em decadência. $\mathrm{O}$ grupo de alunos é de background sócioeconômico misto, embora a baixa classe média esteja fortemente representada.

Essa é a mais moderna "escola corporativa", Northwood Place. A entrada que dá acesso à escola parece um hotel. O saguão tem sofás novos e confrontáveis e uma mesa de centro. Enquanto esperam por chá e biscoitos em louças que combinam, os visitantes podem sentar-se e admirar o conservatório e a piscina. Os funcionários da administração usam uniforme composto de camisa cinza e gravata vermelha. A consciência sobre as prioridades do mercado é evidente na justificativa do diretor para a nova pintura:

Estou apostando comigo mesmo que quando este prédio for remodelado, ficará irreconhecível: o concreto cinza ficará branco, aquelas colunas verdes ficarão amarelo claro, a pintura será creme. Imagino que o prédio ficará em condições de aceitar a matrícula de pelo menos mais 20 alunos. Eu sinto que uma porção de bobagens é dita sobre a nota das crianças.

Por meio da sua aparência cuidadosamente polida e recursos ilimitados, Northwood oferece oportunidades educacionais que, segundo a escola, só podem ser encontradas lá. A escola promete às suas alunas a entrada em um mundo previamente dominado só por homens, "um mundo que exige cada vez mais das mulheres, e no qual a sua contribuição está se tornando cada vez mais significativa". A escola chama a atenção para pesquisas que mostram que as meninas se saem muito melhor, acadêmica e socialmente, em um ambiente "que lhes permite serem livres de distrações e pressões que as escolas para ambos os sexos podem às vezes criar". Os folhetos promocionais da escola falam muito das extensivas facilidades que a escola possui - novas tecnologias, dois laboratórios de computação.

No entanto, havia em geral pouca evidência de que a escola teria sucesso em abrir o horizonte de suas alunas e prepará-las para a prometida "realização na carreira para as mulheres no mundo do amanhã". As meninas ainda demonstravam aspirações fortemente relacionadas ao gênero, quanto à carreira. Apenas algumas

Olhar de professor, Ponta Grossa, 9(1): 11-30, 2006. 
alunas pretendiam seguir carreiras ligadas à ciência. Da mesma forma, apesar da grande promoção da tecnologia através de propaganda e investimento em recursos, um número quatro vezes maior de alunas optou por um exame GCSE em desenvolvimento infantil e apenas uma parte optou por tecnologia.

\section{LOCALIZANDOODETALHEDEN- TRODO MACRO-CONTEXTO}

Para ir além das tendências descritivas da maioria das pesquisas sobre políticas, o que é censurado por Ozga, nesta seção tentamos localizar o detalhe dos quatro estudos de caso dentro do macro-contexto. De acordo com Ozga, o uso de uma análise conjuntural - tal como a teoria centrada no Estado - deveria capacitar-nos para ver através do "caos" e da "falta de lógica" (1990, p. 361) da política e prática e nos concentrarmos nas suas "funções consistentes" e "contradições associadas”. (p. 360).

A teoria centrada no Estado baseia-se na suposição de uma assimetria causal (WRIGHT et al,1992) que, em relação às práticas e políticas educacionais, reivindica a primazia causal do Estado. Embora Ozga e Dale resistam à sugestão de que todo fenômeno pode ser discutido em termos da agenda do Estado, este toma papel central no referencial analítico desses autores. O comentário de Ozga mostra que isso acontece sem que eles cheguem a compreender a centra- lidade do estado: "Nós vamos continuar desmontando e descrevendo todas as partes da máquina sem sermos capazes de explicar tanto como ela funciona como para que ela serve". (1990, p. 361).

Para dar sentido aos quatro estudos de caso, precisamos ligar as respostas locais à agenda do Estado. Entretanto, fazer essas ligações é uma atividade difícil. Mesmo aquelas feitas pelos principais seguidores da teoria são problemáticas. Dale e Ozga, por exemplo, afirmam que a intenção geral de recentes políticas na Grã-Bretanha é a de "restaurar o status quo" (1993, p. 77), no sentido de que elas pressagiam um retorno ao sistema educacional estratificado. Esse resultado é mais do que provável. As escolas dos estudos de caso indicam claramente a fragmentação dos sistemas locais de provisão e o aumento das diferenças entre as escolas. Num nível mais geral, dadas as diferenças em perfil sócioeconômico e características materiais, combinados com as mudanças nos mecanismos de obtenção de fundos, há poucas dúvidas de que haverá uma polarização crescente entre escolas "bem sucedidas" e escolas "fracassadas". No entanto, relacionar tais resultados com o macro-contexto requer mais do que simplesmente olhar para a maneira como as escolas articulam-se umas às outras. Envolve relacionar políticas e processos com os problemas centrais do Estado.

A conexão entre um sistema educacional estratificado e o Estado é re- 
latada por Dale e Ozga (DALE, 1989; DALE; OZGA, 1993) em termos da necessidade de prover da forma mais eficiente uma força de trabalho estratificada adequada. Isso parece refletir uma crise de acúmulo de capital, na qual não há mais excedente o suficiente para cumprir as funções legitimatórias. Mas, enquanto essa explicação faz sentido em um nível, em outro nível ela não é convincente. Por exemplo, onde está a evidência empírica que sugere que o status quo precisava ser restaurado? O que indica que a escola que não realiza seleção para ingresso de aluno era ineficiente em produzir uma força de trabalho estratificada adequada? Apesar de Dale e Ozga sugerirem o contrário, todas as evidências até agora sugerem que os diferentes resultados das escolas que não fazem seleção para o ingresso de alunos são muito semelhantes aos das escolas do sistema tripartite ${ }^{11}$ (por exemplo, HEATH,1987). Da mesma forma, parece-nos inadequado explicar os aspectos da educação progressista em termos de legitimação. Era a escola que não realizava seleção para ingresso de alunos simplesmente mais um exemplo de "compra de favores" (DALE, 1989)?

Um argumento igualmente convincente sustenta que as reformas atuais fortalecem os processos de legi- timação, ao invés de enfraquecê-los. Ball et al (1994) defendem a idéia de que um fator chave da mercantilização da educação é a tendência de colocar a culpa nos pais pelos resultados educacionais desiguais.

A dificuldade de relacionar problemas centrais aos processos e práticas escolares é particularmente séria quando se tenta compreender o que está acontecendo nas escolas que fazem parte dos quatro estudos de caso. Greenbank e Bellevue, como muitas outras escolas (POWER et al, 1994), comprometeram-se na vigorosa promoção dos valores acadêmicos tradicionais, o que pode ser interpretado de um lado como um retorno à educação elitista e seletiva. Mas, na medida em que isso pode contribuir para uma força de trabalho adequadamente estratificada, é difícil perceber como essas escolas respondem à necessidade de suprir os alunos com habilidades adequadas. Será que o tradicionalismo hierárquico da Escola Bellevue é mais relevante às necessidades da economia do que a aprendizagem autodirigida oferecida pela Escola Arneside? É possível sugerir que a educação progressista irá inculcar traços e disposições mais adequadas para uma economia pósfordista.

Dilemas semelhantes também são experimentados ao tentarmos locali-

\footnotetext{
${ }^{11}$ Sistema tripartite refere-se aos três tipos de escolas secundárias: Grammar Schools, Technical e Modern. As escolas que não fazem seleção para ingresso são chamadas Comprehensive Schools (N.E).
}

Olhar de professor, Ponta Grossa, 9(1): 11-30, $2006 . \overline{21}$ 
zar a promoção da educação técnica e científica para as alunas da Escola Northwood no macro-contexto. A "feminização" da força de trabalho (BAKKER,1988) pode nos levar a pensar que esse tipo de desenvolvimento é diretamente responsável ao acúmulo de capital, porque aumenta o interesse de trabalho qualificado tecnologicamente, reduz os custos da força de trabalho e ainda rejeita práticas coletivas (SAYER; WALKER, 1992). Por outro lado, o aumento de mulheres que saem da esfera doméstica pode reduzir a sua função de reproduzir um adequado e barato suprimento de trabalho através da prestação de serviços aos homens em relações PATRIARCAIS (WALBY, 1986). Alternativamente, poder-se-ia afirmar que a defesa da Escola Northwood de formar mulheres com o domínio de conhecimentos científicos é apenas um instrumento de legitimação. Ou é um exemplo de "atividade não relacionada" na qual o Estado age independentemente, "aprisionado na crença de que... a oportunidade educacional melhorada é um fim em si próprio" (OZGA, 1993)? Se isso é verdadeiro, como entendemos os argumentos de que a adoção feminina da reforma individualista neoliberal é inevitável, mas no final das contas um subproduto improdutivo do capitalismo (TILLY; SCOTT, 1987; CHARLES, 1993)?

Todos esses argumentos relacionam o processo local com a agenda do Estado, embora muitos deles sejam mutuamente incompatíveis. No entanto, poderíamos argumentar que essas tensões não são problemas analíticos e sim problemas do capitalismo em si. A busca por conexões diretas e unidimensionais ignora a complexidade fundamental e a natureza contraditória do processo. Certamente a teoria centrada no Estado é vista como representativa de um melhoramento da teoria da correspondência, porque enfatiza a contradição e um grau de indeterminância. Como Ozga sugere, "a teoria centrada no Estado é perfeitamente capaz de acomodar complexidade e diferença" (1990, p. 361).

A noção de contradição é central na posição de Dale e Ozga, mas nem sempre fica claro que função ela tem. $\mathrm{O}$ próprio conceito de contradição pode ser usado de formas contraditórias. Wright et al (1992) identificam pelo menos três formas, as quais estão presentes na exposição de Dale e Ozga. Às vezes, o termo refere-se a uma situação na qual há condições múltiplas para a reprodução de um sistema que não pode ser simultaneamente atendido. Outras vezes, aplica-se a uma situação em que conseqüências não intencionais de uma estratégia subvertem a realização dos objetivos pretendidos. Mas o termo pode também indicar um antagonismo social subjacente que produz conflito. Deixando de lado a confusão analítica que isso cria, o conceito de contradição oferece pouca ajuda para a compreensão da natureza dos processos que podem estar ocorrendo na base. Como 
argumentam Wright et al, o termo é usado "como uma forma de explicar as interações de um conjunto de mecanismos causais" (1992, p. 7), mecanismos que são afirmações apriorísticas e não proposições empi-ricamente sustentáveis.

Dentro da teoria centrada no Estado, é como se o conceito fosse usado para esconder a confusão, em vez de clarificar o processo. Preocupações de que as coisas podem não se encaixar com a teoria somente indicam quão complexos e contraditórios são os problemas do Estado. Tal fato permite a introdução de um forte elemento de indeterminância, para apoiar a teoria. Com referência aos três problemas centrais do Estado, por exemplo:

Dever-se-ia observar que a identificação de problemas não significa que a identificação automática da solução dos mesmos seja possível, nem tão pouco significa que o aparato do Estado é efetivamente elaborado para lidar com esses problemas. A atividade relacionada aos problemas centrais não dá conta de tudo que o Estado faz atividade destinada a soluções ineficientes pode tornar-se um fim em si mesma... (OZGA,1993, p. 4)

Como Saunders (1986) comenta, ao se referir a referenciais analíticos semelhantes, "mesmo que eventos não pareçam suportar a teoria, isso não a invalida, porque eventos refletem condições contingentes enquanto a teoria diz respeito aos mecanismos necessários que existem mesmo que eles não se manifestem" (p. 356).

As implicações dessa posição para a elucidação empírica da teoria centrada no Estado são profundas. Requer que se façam distinções entre eventos que refletem meramente condições e aqueles que são manifestações de mecanismos necessários. Mas a teoria prevê poucas pistas de como isso pode ser feito. Como um passo preliminar, poder-se-ia se considerar que características são duradouras e quais são efêmeras. Mas mesmo isso pode ser problemático. Por exemplo, o que é normalmente considerado propriedade duradoura, pode ter sido fabricado recentemente. $\mathrm{O}$ tradicionalismo reinventado de Bellevue é mais completo do que qualquer outro que a escola experimentou como uma autêntica Grammar School. Pelo fato de poder apoiar-se em um poderoso legado, o órgão de tubos da escola e o refeitório cujos azulejos foram trocados são mais novos do que seu laboratório de informática. O tradicionalismo revigorado de Bellevue é certamente mais recente que a adesão continuada de Arneside aos ideais da escola progressista não-seletiva.

Outra estratégia para separar a superfície de propriedades mais profundas pode ser a comparação da 'retórica' com a 'realidade'. Manifestações públicas da identidade educacional de uma escola certamente nunca deveriam ser consideradas de forma acrítica, mas precisariam ser interrogadas de forma cética. Vejamos o exemplo da Escola Northwood: sua falta de sucesso em ampliar os horizontes das garotas pode sugerir que

Olhar de professor, Ponta Grossa, 9(1): 11-30, 2006. 
os ideais feministas são tão superficiais quanto a proposta de pintura. Da mesma forma, as tentativas da Escola Greenbank de celebrar diferenças culturais devem ser vistas com cautela. É muito pouco provável que Urdu e Bengali possam igualar-se às línguas européias, pois elas não estão disponíveis para a maioria academicamente mais capaz. Nem a introdução de estudos islâmicos pode ser vista como uma estratégia eficiente para a promoção de uma herança cultural alternativa enquanto os estudos islâmicos não forem uma das opções de exames. No entanto, é difícil desconsiderar estes aspectos como meramente 'retóricos'. Como Bernstein argumenta, tais distinções pejorativas têm pouco valor: "aquilo que é superfície para uma pessoa pode significar princípio subjacente para outra e vice-versa" (1990, p. 167). A celebração de diferenças culturais na Escola Greenbank pode ser contraproducente, a filiação à idéia de mulheres "poderosas" na Escola Northwood pode não ser realizável. Mas isso não significa que esses desenvolvimentos não sejam importantes. Novamente Bernstein diz: "Porque essas características são superficiais, não significam que elas não tenham uma considerável importância" (1977, p. 160).

Em relação às mudanças educacionais, a atribuição de significado parece ter sido determinada tanto por valores quanto por evidências. Por exemplo, a importância que nós damos a alguma coisa parece produzir uma proporção inversa ao resultado desejado (POWER, 1992). A aparência de características que nós provavelmente aprovaremos, tais como o envolvimento da comunidade ou uma escola "favorável às garotas", são consideradas contingências efêmeras e superficiais, enquanto que aspectos que desaprovamos são vistos mais como mecanismos necessários. Essa tendência é particularmente forte quando se trabalha com processos educacionais baseados em uma teoria centrada no Estado. Ela tem, como já vimos, uma preferência inerente de enfatizar continuidade ao invés de mudança, coerência ao invés de incoerência.

No entanto, é incorreto desconsiderar detalhes inconvenientes como sendo meramente superficiais ou contingentes, assim como é incorreto sugerir que toda mudança representa uma reestruturação radical do cenário educacional. Os critérios de significância devem ser tanto uma questão empírica como uma afirmação à priori. Porém, é difícil ver como uma teoria centrada no Estado fornece os meios para lidar com o aspecto empírico. Embora uma relação causal entre propriedade essencial e manifestação superficial esteja no centro de teorias como essa, não há "direções claras (a não ser os próprios interesses condicionados por valores do pesquisador) para determinar o que é necessário e o que é contingente" (SAUNDERS, 1986). 
Certamente, dentro de uma teoria centrada no Estado, estabelecer conexões entre o macro contexto e os processos locais pode ser bastante arbitrário. Parece envolver um número de saltos conceituais que freqüentemente se fundamentam em afirmações não examinadas e não examináveis, ao invés de se basearem em raciocínio com base empírica e analiticamente consistente. Especificamente, a teoria centrada no Estado fornece poucos princípios para separar o que é superficial e efêmero do que tem propriedades mais profundas. A teoria centrada no Estado também não fornece diretrizes para relacionar uma agenda especificada pelo Estado com a prática local. Tais relações parecem ser um grande trabalho de adivinhação. E se a maior parte da confusão é considerada em termos de propriedades irredutíveis, então qual é o valor de se fazer referência ao macro-contexto? Enquanto a afirmação sobre a importância do Estado sugere uma assimetria causal (WRIGHT et al, 1992), a afirmação simultânea de indeterminância torna a manisfestação e as conseqüências dessa assimetria fora do alcance da validação empírica.

A teoria centrada no Estado não tem potencial para o que Saunders chama de "contra-fatualidade": "a necessidade de toda teoria apoiar a possibilidade de desconfirmar instâncias e estipular os critérios pelos quais tais instâncias podem ser reconhecidas em pesquisas empíricas" (1986, p. 361). De fato, cada exemplo de desconfirmação em potencial simplesmente confirma a teoria. A inconsistência é o resultado inevitável de contradições (em todas as suas facetas), dinâmicas intervenientes e propriedades irredutíveis.

Embora a teoria centrada no Estado possa oferecer uma explicação mais sofisticada da relação entre economia e educação do que outras teorias, ela faz isso à custa da possibilidade de ser testada. Pelo menos foi possível ter, empiricamente, um debate acerca das afirmações de Bowles e Gintis (1976). Os autores forneceram um referencial sustentável ou refutável, referencial amplo e conjuntural com o qual se pode relacionar o detalhe com o macro-contexto. De fato, a eventual rejeição da teoria da correspondência como uma descrição adequada foi baseada tanto em pesquisa empírica quanto em inconsistência teórica, ou na desaprovação da idéia de indeterminância. (HOGAN, 1981; MACDONALD, 1988). A incorporação de contradição e indeterminância que Dale e Ozga fazem dentro de um referencial marxista da primazia causal do Estado torna a sua teoria empiricamente não-demonstrável.

Resumindo, a teoria centrada no Estado não oferece um referencial adequado para descrever os detalhes. Se Bernstein está correto ao afirmar que "qualquer teoria é tão boa quanto os princípios de descrição que ela origina" (1992, p. 5-6), então é preciso dizer que a teoria centrada no Estado tem 
pouco a contribuir nesse sentido.

\section{RECONCEITUALIZANDO O} MACRO-CONTEXTO

As dificuldades encontradas em relacionar a micro-investigação com a macro-análise levaram a questões não apenas relativas às especifi-cidades da teoria centrada no Estado, mas também à forma como ela é construída.

As afirmações da teoria centrada no Estado são construídas com base em uma série de oposições que são difíceis de serem defendidas e em última instância inúteis, na medida em que dificultam o diálogo. Teóricos que adotam uma abordagem estadocêntrica afirmam que estão preocupados com "questões mais amplas", ou seja, com o macro-contexto. Eles identificam 'coerência' e 'consistência'. Aqueles que tratam das micro-investigações, por outro lado, estão interessados nos 'detalhes'. O trabalho deles envolve 'o acúmulo de informações' e a 'coleta de descrições ricas'. Longe de olhar propriedades duradouras, encontram "improviso", “acaso" e “confusão'. É interessante observar que o antônimo de Ozga para "uma proposição sustentável a priori" é "explicação improvisada" (1993, p. 2).

Essa representação adversa de outras orientações ao estudo de política educacional é provavelmente o resultado da "abordagem de paradigmas" à qual nos referimos anteriormente(BERNSTEIN,1977; DAVIES,
1994). Nesse caso, o pluralismo é comparado com as perspectivas marxistas. Tal justaposição freqüentemente baseia-se no exagero das diferenças entre os dois modelos. De fato, o comentário de Ozga de que interpretações pluralistas "parecem meras descrições" implica uma ausência de sofisticação teórica, o que passa a impressão de que macro-analistas detêm o monopólio da teoria. Como Whitty e Edwards (1994) afirmam em relação às críticas de Grace (1991) e Ozga (1990) sobre pesquisas da área de políticas,

[...] há uma implicação ... de que ter base teórica significa ser orientado por uma forma de teoria particular...Há também uma tendência das críticas de tais trabalhos em considerar micro-estudos como descritivos e macro-estudos como analíticos, quando na realidade ambos podem ser uma e outra coisa (p. 12).

Em certos aspectos, o aumento dos macro-estudos é pouco surpreendente. Como em outras explicações não-convencionais, teorias centradas no Estado podem conter alegações mais amplas quanto à verdade do que perspectivas dispersas. Afinal, somente um ponto de vista "desmonta e descreve todas as partes da máquina", enquanto outra teoria pode explicar como ela funciona e para que serve". (OZGA, 1990) A crítica de Saunder ao realismo também se aplica à teoria centrada no Estado:

[...] ela não somente torna as teorias existentes imunes à falsificação como 
permite pesquisas empíricas, mas ela também acrescenta a vantagem de que outras teorias (que podem ser refutadas com bases políticas) podem ser dispensadas como metodologicamente incorretas. Abordagens nãomarxistas podem ser condenadas como superficiais - se vistas apenas como acontecimentos notórios deixando de apreciar as causas reais que as apresentaram (1986, p. 361).

Essa suposta superioridade não apenas leva os macro-analistas a se considerarem em vantagem teórica, mas há também uma crença implícita e, às vezes, explícita de que os seus argumentos são moralmente melhores, o que pode levar a uma "caça às bruxas e a acusações de heresia" (BERNSTEIN, 1977, p. 158). Assim, fica-se com a impressão de que mesmo que se chame atenção para a mudança ao invés de continuidade, isso significa arriscar o preço do pluralismo por invocar o poder de intervenção sobre as estruturas de capital. Vista desse ângulo, a contribuição do pluralismo torna-se não somente uma acusação de cegueira teórica, mas de irresponsabilidade política. Nesse contexto, Dale (1994) e Ozga (1993) citam a distinção que Cox faz entre "a teoria de resolução de problemas" e a "teoria crítica": aqueles que se juntam à primeira idéia - que inclui qualquer um que poderia ser visto como propagador de ideais pluralistas - devem ser criticados não somente porque produzem "um resultado e relato superficial" (OZGA, 1993, p. 16), mas porque estão aparentemen- te menos interessados nas questões mais amplas e nas desigualdades de poder. Eles podem, portanto, servir para reproduzir e reforçar os processos que descrevem com isenção, aceitando os problemas de grupos dominantes (por exemplo, GORDON, 1989). Esse tipo de prática pode não apenas levar a uma falsa representação do trabalho de outros, mas poderia também contribuir para a estagnação da formulação de teorias. Sem dúvida, Saunders afirma que são afirmações espúrias e duvidosas para uma epistemologia "privilegiada" que tem "consistentemente enfraquecido, ao invés de fortalecer o impacto político do marxismo nos últimos cem anos" (1986, p. 355). A importância de se posicionar além dessa justaposição tem sido amplamente expressa. McLennan (1989), por exemplo, sugere que a "oposição histórica" precisa ser revista para se poder tratar de assuntos contemporâneos. Wright et al (1992) argumentam que abordagens marxistas devem ser reconstruídas para poderem sobreviver - uma tarefa que "vai inevitavelmente corroer as fronteiras separando o marxismo de alguns de seus rivais".

Análises de outras abordagens analíticas, notadamente pós-estruturalistas, sugerem que a mera divisão de macro e micro é agora mais difícil de ser sustentada. E a supremacia moral e teórica que coloca os referenciais macro-analíticos acima das micro-investigações é igualmente suspeita. A metáfora de Ozga sobre 
a máquina e seus componentes reflete a possivelmente ultrapassada crença na validade do argumento do tipo "soma" e "partes". Tal metáfora pode agora ser mais um impedimento do que uma fonte de conhecimento. Como Wright et al observam:

A questão se avoluma no que significa 'soma' e 'partes'. Uma maneira de entender a afirmação holística é a seguinte: as partes da sociedade são os indivíduos como propriedades de particulares, por exemplo, propriedades que podem ser definidas por cada indivíduo independentemente de todos os outros indivíduos. O todo, então, é maior do que a 'soma' destas partes no sentido de que as propriedades do todo vem de padrões sistemáticos de relações de interação entre estes indivíduos - as relações que os une - e não simplesmente do aglomerado de suas propriedades individuais (isto é, não dependentes de relações). Por outro lado, se as propriedades relacionais são incluídas na descrição das partes em si, então não é verdade que o todo é mais do que a soma de suas partes. Tudo que foi incluído na palavra 'maior' na fórmula holística foi agora incluído na re-descrição das 'partes' (1992, p. 111-112).

Para finalizar, talvez seja útil retornar à crítica original de Ozga. A autora argumenta que a não ser que possamos mostrar o papel que a parte detalhada exerce no macro-contexto, nós estaremos ocupados, mas cegos. Poderia, no entanto, ser mais apropriado partilhar o ônus da responsabilidade e sugerir que é tão importante para os teóricos da abordagem centrada no Estado demonstrar o papel que o macro-contexto exerce nos relatos mais detalhados.

\section{Agradecimentos}

Agradeço a David Halpin e Geoff Whitty por seus comentários sobre a versão preliminar deste artigo.

\section{REFERÊNCIAS}

BAKKER, I. Women's employment in comparative perspective. In: JENSON, J HAGEN, E.; REDDY, G. (Ed.). Feminisation of labour force: paradoxes and promises. Oxford: Polity, 1988.

BALL, S. J. Politics and policy-making in education. London: Routledge, 1990.

BALL, S. J.; BOWE, R.; GEWIRTZ, S. Market forces and parental choice. In: TOMLINSON, S. (Ed.). Education reform and its consequences. London: Institute of Public Policy Research/Rivers Oram Press, 1994.

BERNSTEIN, B. Class, codes and control. London: Routledge \& Kegan Paul, 1997. v. 3.

BERNSTEIN, B. Code theory and research. Barcelona: El Roure, 1992. v. 5.

BERNSTEIN, B. The structuring of pedagogic discourse. London: Routledge, 1990.

BOWE, R.; BALL, S. J.; GOLD, A. Reforming Education and Changing Schools: case studies in policy sociology. London: Routledge, 1992.

BOWLES, S.; GINTIS, H. Schooling in capitalist america. London: Routledge \& Kegan Paul, 1976. 
CHARLES, N. Gender divisions and social change. Hemel Hempstead: Harvester Wheatsheaf, 1993.

DALE, R.; OZGA, J. Understanding education policy: principles and perspectives. Buckingham: Open University Press, 1991. (E333 Module 1).

DALE, R.; OZGA, J. Two hemispheres, both new right? 1980s education reform in New Zealand and Wales. In: LINGARD, J.; KINGHT PORTER, P. (Ed.). Schooling reform in hard times. London: Farmer, 1993.

DALE, R. The state and education policy. Milton Keynes: Open University Press, 1989.

DALE, R. Applied education politics or political sociology of education? Contrasting approaches to the study of recent education reform in England and Wales. In: HALPIN, D.; TROYNA, B. (Ed.). Researching education policy: ethical and methodological issues. London: Falmer, 1994.

DAVIES, B. Durkheim and sociology of education. British Journal of Sociology of Education, n. 15, p. 3-26, 1994.

FITZ, J.; HALPIN, D.; POWER, S. Grantmaintained schools: education in the marketplace. London: Kogan Page, 1993.

GORDON, L. Review symposium on 'Governing Education' (A. McPherson\& C.D. Raab). British Journal of Sociology of Education, n. 10, p. 105-109, 1989.

GRACE, G. Welfare labourism versus the new right: the struggle in New Zealand's education policy. In: ERA RESEARCH NETWORK, University of Warwick, 28 nov. 1991.

HALPIN, D.; FITZ, J. Researching grantmaintained schools. Journal of Education
Policy, n. 5, p. 223-242, 1990.

HATCHER, R.; TROYNA, B. The 'policy cycle': a ball by ball account. Journal of Education Policy, n. 5, p. 155170, 1994.

HEATH, A. Class in the classroom. New Society, p. 13-15, 17 July, 1987.

HOGAN, D. Capitalism, liberalism and schooling. In: DALE, R.; ESLAND, G; FERGUSSON, R.; MACDONALD, M. (Ed.). Education and the State: schooling and the national interest. Lewes: Falmer, 1981. v. 1.

MCDONALD, P. Historical school reform and the correspondence principle. In: COLE, M. (Ed.). Bowles and Gintis revisited: correspondence and contradiction in educational theory. London: Falmer, 1988.

MCLENNAN, G. Marxism, pluralism and beyond. Cambridge: Polity, 1989.

OFFE, $\mathrm{C}$. The theory of the capitalist state and the problem of policy-formation. In: LINDBERG, L.; ALFORD, R.; OFFER, C. (Ed.). Stress and contradiction in modern capitalism. Lexington Books, 1975.

OFFE, C. Contradictions of the welfare state. London: Hutchinson, 1984.

OFFE, V. Disorganized capitalism. Cambridge: Polity, 1985.

OZGA, J. Policy research and policy theory: a comment on Fitz and Halpin. Journal of Education Policy, n. 5, p. 359-362, 1990.

OZGA, J. Theorizing education policy sociology. In: THE CONFERENCE NEW DIRECTIONS IN EDUCATION POLICY SOCIOLOGY. Southampton, 30-31 Mar, 1993. 
POULANTZAS, N. Political power and social classes. London: New Left, 1973.

POWER, S. Researching the impact of education policy: difficulties and discontinuities. Journal of Education Policy, n. 7, p. 493-500, 1992.

POWER, S.; HALPIN, D.; FITZ, J. Underpinning choice and diversity? The grant-maintained schools policy in context. In: TOMLINSON, S. (Ed.).

Educational reform and its consequences. London: Institute of Public Policy Research/Rivers Oram Press, 1994.

RAAB, C. D. Theorising the governance of education. British Journal of Educational Studies, n. 42, p. 6-22, 1994.

SAUNDERS, P. Social theory and the urban question. London: Unwin Hyman, 1986.

SAYER, A.; WALKER, R. The new social economy. Osford: Blackwell, 1992.

TILLY, L.; SCOTT, J. Women, work and family. London: Methuen, 1987.

WALBY, S. Patriarchy at work. Oxford: Polity, 1986.

WHITTY, G.; EDWARDS, T. Researching Thatcherite education policy. In: WALFORD, G. Researching powerful in education. London: UCL Press, 1994.

WRIGHT, E. et al. Reconstructing marxism: essays on explanation and the theory of history. London: Verso, 1992.

Encaminhado em: 07/02/06

Aceito em: 15/02/06 